\title{
Gene flow between arrhenotokous and thelytokous populations of Venturia canescens (Hymenoptera)
}

\author{
MV Schneider ${ }^{1}$, G Driessen ${ }^{1,2}$, LW Beukeboom ${ }^{3}$, R Boll ${ }^{4}$, K van Eunen, A Selzner, J Talsma and \\ L Lapchin ${ }^{4}$ \\ ${ }^{1}$ Animal Ecology, Institute of Evolutionary and Ecological Sciences, University of Leiden, PO Box 9516, NL-2300 RA, Leiden, The \\ Netherlands; ${ }^{2}$ Free University, Institute of Ecological Sciences, De Beelelaan 1085, $1081 \mathrm{HV}$, Amsterdam, The Netherlands ${ }^{3}$ Evolutionary \\ Genetics Group, Biological Centre, University of Groningen, Kerklaan 30, NL-9751 NN Haren, The Netherlands; ${ }^{4}$ INRA - Centre de \\ Recherches d'Antibes, UMR 1112 ROSE, 'Response des Organisme aux Stress Environnementaux', 37, Boulevard du Cap BP 2078, \\ 06606 Antibes Cedex, France
}

In the solitary parasitoid wasp Venturia canescens both arrhenotokously (sexual) and thelytokously (parthenogenetical) reproducing individuals occur sympatrically. We found in the laboratory that thelytokous wasps are able to mate, receive and use sperm of arrhenotokous males. Using nuclear (amplified fragment length polymorphism, virus-like protein) and mitochondrial (restriction fragment length polymorphism) markers, we show the occurrence of gene flow from the arrhenotokous to the thelytokous mode in the field. Our results reinforce the paradox of sex in this species. Heredity (2003) 90, 260-267. doi:10.1038/sj.hdy.6800245

Keywords: gene flow; Venturia canescens; thelytoky; arrhenotoky; evolution of sex

\section{Introduction}

Although asexual reproduction could offer considerable fitness advantages over sexual reproduction most eukaryotes reproduce sexually (Bell, 1985; Maynard Smith, 1986; Kondrashov, 1993; Dybdahl and Lively, 1995; Hurst and Peck, 1996; West et al, 1999). If $s$ is the proportion of males in the offspring and asexual and sexual reproduction would result in equal numbers of offspring with equal viability, then asexual females would produce 1/ $(1-s)$ times more reproducing offspring than sexual females (Williams, 1975; Maynard Smith, 1978). For most organisms $s$ is close to 0.5, and therefore asexual reproduction hypothetically has an instantaneous twofold advantage compared to sexual reproduction.

Hence, whenever the two reproductive strategies would compete, the elimination of the sexual mode is expected unless there are factors that counterbalance the disadvantages of sexual reproduction (Hurst and Peck, 1996; Peck et al, 1998; Peck and Waxman, 2000; Corley et al, 2001). Presently, the most supported explanations for the maintenance of sexual reproduction are that sexual reproduction (1) allows deleterious mutations to be eliminated more efficiently (Muller's ratchet and mutational deterministic model) (Muller, 1964; Kondrashov, 1988), (2) accelerates adaptation to changing environments (the Red Queen hypothesis) (Van Valen, 1973) and (3) enables a wider range of niche exploitation (the Tangled Bank hypothesis) (Bell, 1985). These hypotheses are not mutually exclusive and operate on different time scales (West et al, 1999). For example,

Correspondence: MV Schneider, Institute of Evolutionary and Ecological Sciences, Section Animal Ecology, Leiden University, PO Box 9516, 2300 RA Leiden, The Netherlands. E-mail: mvschneider@rulsfb.leidenuniv.nl
Muller's ratchet acts on an evolutionary time scale generally longer than that at which the Red Queen hypothesis works, while the Tangled Bank hypothesis accentuates the more immediate ecological advantages.

Although empirical support for these explanations is not overwhelming (but see: Lamb and Willey, 1979; Leslie and Vrijenhoek, 1980; Lively, 1987; Lively et al, 1990; Jokela et al, 1997; Corley and Moore, 1999; Storhas et al, 2000; Kramer and Templeton, 2001); the robustness of sexual reproduction against asexual competitors at evolutionary and ecological time scales is at least theoretically underpinned (Lynch, 1984; Kondrashov, 1993; Charlesworth et al, 1993; Hurst and Peck, 1996; Peck et al, 1997; Peck et al, 1998; Barton and Charlesworth, 1998; West et al, 1999).

Although sexual reproduction is the predominant mode in plants and animals, many species belonging to many different taxa are known to reproduce asexually and sometimes simultaneously occur with sexual counterparts (Parker et al, 1977; Lynch, 1984; Bierzychudek, 1985, 1989; Vrijenhoek, 1999). This implies that in these cases long-term mechanisms must operate that prevent asexual reproduction from elimination, despite the evolutionary limitations imposed by the limited genetical variation resulting from the absence of recombination. There are three mechanisms that could favor the long-term maintenance of asexual reproduction. First, the preservation of some degree of genetical variation among offspring (Parker et al, 1977; Vrijenhoek, 1979; Slobodchikoff, 1983). In Hymenoptera several cytological mechanisms for restoring diploidy exist, which can preserve (some) heterozygosity (Suolmalainen et al, 1987). A second mechanism could be the recurrent arisal of new asexually reproducing lineages in sexual populations through the production of unreduced gametes or 
double fertilization (Templeton, 1979; Suolmalainen et al, 1987; Pongratz et al, 1998; Delmotte et al, 2001; Kramer and Templeton, 2001). A special example of this are cytoplasmatically inherited Wolbachia bacteria that can induce gamete duplication in which the meiotically produced haploid egg undergoes an extra round of DNA replication without cell division (Legner, 1985; Stouthamer and Kazmer, 1994; Werren, 1997). Finally, it has been shown that gene flow from sexual males to asexual females through mating between males and asexual females can lead to new asexual lineages (Innes and Hebert, 1988; Browne, 1992; Belshaw et al, 1999; Delmotte et al, 2001).

In this study we investigate the consequences and significance of gene flow between sexual and parthenogenetic individuals in a parasitic wasp in the lab and under field conditions. In the Hymenoptera, asexual reproduction is generally referred to as thelytoky, (ie unfertilised eggs developing into diploid females and males being absent), whereas sexual reproduction is referred to as arrhenotoky (ie unfertilised eggs developing into haploid males and fertilised eggs developing into diploid females). Arrhenotoky is the predominant reproductive system in the order and supposed to be ancestral (Cook, 1993). In accordance with these definitions we will use thelytoky to refer to asexual reproduction and arrhenotoky to refer to sexual reproduction. In the solitary parasitoid wasp Venturia canescens (Gravenhorst) arrhenotokously and thelytokously reproducing populations occur sympatrically (Schneider et al, 2002).

In $V$. canescens both arrhenotoky and thelytoky are obligate, while the latter is not caused by Wolbachia bacteria but most likely has a genetical basis (Beukeboom and Pijnacker, 2000). Thelytokous females produce haploid eggs that undergo diploidisation and develop parthenogenetically into females only. Diploidy restoration occurs through abortion of a reduction division and metaphase I restitution (Speicher et al, 1965; Beukeboom and Pijnacker, 2000). The genetic consequences are similar to central fusion automictic parthenogenesis (Suolmalainen et al, 1987). Distal loci will become homozygous over time, whereas proximal loci can maintain heterozygosity depending on the localisation of crossovers. Sex determination in $V$. canescens occurs according to the single-locus model (Whiting, 1943; Beukeboom, 2001). Individuals heterozygous at the sex locus develop into females, whereas hemizygous (normal haploid) individuals develop into males. Homozygosity at the sex locus in diploids results in diploid males. Since thelytokous females never produce (diploid) males, the sex locus must remain heterozygous and hence be located close to a centromere in $V$. canescens (Crozier, 1971; Beukeboom and Pijnacker, 2000).

$V$. canescens is a widely used biological model in behavioural, population dynamical, genetical and physiological studies, and the earliest publications date back to the 1930s. Except for two very recent publications (Beukeboom et al, 1999; Schneider et al, 2002), it has always been reported as having obligate thelytokous reproduction. There are two likely reasons for this. First, many of these studies made use of a few commonly shared laboratory strains. The second reason is that many of the hosts of $V$. canescens are stored product pests and strains were typically collected from bakeries, granaries, and dried fruit warehouses (Waage, 1979;
Press et al, 1982; Cline et al, 1983; Driessen et al, 1995; Harvey and Vet, 1997; Bonsall and Hassell, 1998). These places provide a relatively constant environment and ample supply of pyralid hosts (Freeman, 1980; Goater, 1986; Harvey and Thompson, 1995). Under such conditions arrhenotokous populations are likely to be rapidly outcompeted by thelytokous ones. Regular shipments of products between granaries and warehouses can spread a thelytokous strain rapidly over a large region once it has appeared. Therefore, these places may serve as source populations from which thelytokous wasps can enter the environment.

Laboratory observations suggested that thelytokous females do sometimes mate with arrhenotokous males and receive sperm, potentially leading to gene flow between both modes. We present the results of laboratory experiments on gene transfer from arrhenotokous males to thelytokous females of $V$. canescens using nuclear VLP (virus-like particles, Hellers et al, 1996) and (amplified fragment length polymorphism (AFLP), Vos et al, 1995) markers. Furthermore, we investigate whether gene transfer occurs under field conditions. We compare mitochondrial restriction fragment length polymorphism (RFLP) haplotypes with VLP and AFLP nuclear profiles of wasps of both modes caught in the field. The cytoplasmically inherited mitochondrial markers provide a female-to-female genealogy regardless of the mode of reproduction, while nuclear markers enable the detection of recombination within arrhenotokous but more importantly between thelytokous and arrhenotokous wasps.

\section{Materials and methods}

\section{Gene transfer from males to thelytokous females under} laboratory conditions

To screen for gene transfer between the two different reproductive modes, the VLP-gene $p 40$ (Hellers et al, 1996) was used. This is a convenient marker because it has two allelic variants differing in a $54 \mathrm{bp}$ sequence which is absent in the so-called 'minus' variant and present in the 'plus' variant. They can be easily distinguished on an agarose gel. When a homozygous female is crossed with a hemizygous male carrying the other variant, the VLP allele composition in the offspring can be used to check whether there has been gene transfer or not. Isofemale lines either homozygous +/ were set up for both reproductive modes. The wasps used in the crosses came from a lab culture founded with wasps collected in 1999 in the South of France (Côte d'Azur). The wasps were reared on Ephestia kuehniella Zeller (Lepidoptera: Phycitidae) at $25^{\circ} \mathrm{C}, 16 \mathrm{~L}: 8 \mathrm{D}$.

To obtain crosses between modes, 10 thelytokous homozygous females and 20 arrhenotokous males carrying the other VLP allele were put into a transparent sleeve cage $\left(51 \times 35 \times 35 \mathrm{~cm}^{3}\right)$. The age of the wasps varied between 1 and 5 days. Upon mating, couples were separated from the others by putting a glass tube over them. After mating, the males were frozen at $-80^{\circ} \mathrm{C}$, and the females were kept in the tube until the end of the day. Both arrhenotokous and thelytokous $V$. canescens females are somewhat reluctant to mate under laboratory conditions. Therefore, this procedure had to be repeated for several days in order to get a sufficient number of 
crosses. In total, 50 crosses between VLP +/+ females and VLP - males were obtained, and 11 crosses between VLP - / - females and VLP + males. At the end of each day, each mated female was given approximately 20 hosts in a jar for $24 \mathrm{~h}$ after which they were transferred to a new jar with 20 hosts for another $24 \mathrm{~h}$. Thereafter, they were frozen at $-80^{\circ} \mathrm{C}$ and the hosts were reared at $25^{\circ} \mathrm{C}$.

$\mathrm{F}_{1}$ virgin females were allowed to oviposit for $24 \mathrm{~h}$, after which they were checked for their VLP-allele composition (see below). Parasitised hosts were put at $25^{\circ} \mathrm{C}$ till the progeny $\left(\mathrm{F}_{2}\right)$ emerged. The $\mathrm{F}_{2}$ virgin female offspring was set on hosts again and also checked for their VLP-gene, and so on until the $\mathrm{F}_{4}$ generation. Five of the original 50 crosses were used for an AFLP analysis in order to follow the inheritance of unique father bands in the $F_{1}, F_{2}$, and in some cases $F_{3}$ and $F_{4}$ generation.

\section{Gene transfer from males to thelytokous females in the field}

In this study, the occurrence of gene transfer was investigated around a potential source population of thelytokous wasps: a company producing Trichogramma parasitoids for biological control in Valbonne in the south of France. The Trichogramma wasps are produced on the eggs of the Mediterranean flour moth Ephestia kuehniella, a moth species whose larvae are attacked by $V$. canescens. In the year preceding this survey (1998) about 4060 $V$. canescens were counted on sticky traps that had been installed inside the company building. Not one of them was a male, which strongly suggests that the population inside the company was a purely thelytokous one. Baits positioned outside at $500 \mathrm{~m}$ distance of the factory in 1998 revealed that both arrhenotokous and thelytokous wasps occurred in the direct surroundings.

During 1999 'wild' wasps were allowed to oviposit in baits along three $500 \mathrm{~m}$ transects radiating from the company building. One bait was placed inside the building, one directly outside and three times five baits along the three transects at an interbait distance of $100 \mathrm{~m}$ each. Baits consisted of a cotton screen bag (approximately $20 \times 20 \mathrm{~cm}^{2}$ ), containing third instar larvae of $E$. kuehniella settled in their food medium (semolina). These baits have been shown to be equally attractive to arrhenotokous and thelytokous wasps in dispersal experiments in the field (I Amat personal communication). The baits were collected and replaced every week during the season (March-September).

Baits were left out for 1 week during which adult females could visit them and lay eggs in the host larvae through the screen bag. Afterwards, the baits were collected and taken into the laboratory where they were checked daily for emerging wasps. Each emerging female $\left(F_{1}\right)$ was set up as an isofemale line in order to determine her reproductive mode after which she was stored at $-80^{\circ} \mathrm{C}$ for later DNA analysis. If only females (at least five) occurred in the offspring, the $\mathrm{F}_{1}$ mother was scored as thelytokous, if only males or males and females occurred in the offspring, the $F_{1}$ mother was scored as arrhenotokous. If an emerging female produced fewer than five daughters and no sons, these daughters were bred one more generation to ascertain that they were thelytokous. Note that wasps emerging from a single bait could be siblings because a single visiting female may have oviposited in more than one host larva. Therefore, from baits producing more than one wasp of either mode only one thelytokous and/or one arrhenotokous wasp was included in our molecular analysis. Wasps were reared at $25^{\circ} \mathrm{C}$ and 16L:8D on fifth instar E. kuehniella caterpillars raised on semolina.

From each site and collection date of which material was available, one wasp of each reproductive mode was chosen for molecular analysis. To verify the occurrence of sporadic sexual processes in thelytokous females in the field, we carried out a molecular analysis based on the nuclear genome in combination with mtDNA. The latter, being exclusively maternally inherited would reflect the genealogy that is not affected by possible recombination of the nuclear genome. Incongruities between the relatedness of the wasps based on the nuclear genome and the mitochondrial haplotypes would indicate gene flow from arrhenotokous to thelytokous wasps.

\section{Nuclear DNA analysis}

DNA was extracted as described in Schneider et al (2002). For amplification of the VLP $p 40$ gene, we used the specific primers (5'-CTCAATATGTGGGGTGGTGG-3' and 5'-TCGCAGTGGCTTGTCAGAGT-3') (Hellers et al, 1996). PCR was carried out with $4 \mathrm{U}$ Taq polymerase (Amersham), $2.5 \mu \mathrm{l}$ Taq buffer, $10 \mathrm{mM}$ dNTPs and $100 \mathrm{pmol}$ primer (total volume $25 \mu \mathrm{l}$ ). The PCR profile was $94^{\circ} \mathrm{C}$ for $2 \mathrm{~min}, 30$ cycles of $94^{\circ} \mathrm{C}$ for $0.43 \mathrm{~min}, 65^{\circ} \mathrm{C}$ for $1 \mathrm{~min}, 72^{\circ} \mathrm{C}$ for $1 \mathrm{~min}$ and one cycle of $72^{\circ} \mathrm{C}$ for $1 \mathrm{~min}$. PCR products were separated on $1.5 \%$ agarose gels and stained with ethidium bromide. The AFLP technique (Vos et al, 1995) used in this study is described in Schneider et al (2002).

\section{Mitochondrial DNA analysis}

Amplification of a $1400 \mathrm{bp}$ mitochondrial DNA region was achieved using the primers $5^{\prime}$-TTGATTTTTTGGTCATCCAGAAGT-3' and 5'-CCACAAATTTCTGAACATTGACCA-3' and amplification of another $3000 \mathrm{bp}$ region using the primers 5'-GAGCTTCAACATGAGCTTT-3' and 5'-AAACTAGGATTAGATACCCTATTAT-3'. Amplifications were made in $50 \mu \mathrm{l}$ reaction volumes containing $1 \times$ PCR buffer (Amersham), $10 \mathrm{mM}$ dNTPs, $1 \mathrm{U}$ Taq polymerase (Amersham) and 5 pmol of each primer. The PCR profile for the first fragment was one cycle at $95^{\circ} \mathrm{C}$ for $1 \mathrm{~min}, 35$ cycles of $94^{\circ} \mathrm{C}$ for $1 \mathrm{~min}, 60^{\circ} \mathrm{C}$ for $1 \mathrm{~min}, 72^{\circ} \mathrm{C}$ for $1 \mathrm{~min} 30 \mathrm{~s}$ and one cycle at $72^{\circ} \mathrm{C}$ for $5 \mathrm{~min}$. For the fragment of $3000 \mathrm{bp}$, the PCR profile was one cycle at $93^{\circ} \mathrm{C}$ for $1 \mathrm{~min}$, followed by 14 cycles of $93^{\circ} \mathrm{C}$ for $1 \mathrm{~min}$ and $60^{\circ} \mathrm{C}$ for $12 \mathrm{~min}$ and 25 cycles of $93^{\circ} \mathrm{C}$ for $1 \mathrm{~min}$ and $60^{\circ} \mathrm{C}$ for $12 \mathrm{~min}$ increasing $15 \mathrm{~s}$ each step, and one final cycle at $72^{\circ} \mathrm{C}$ for $7 \mathrm{~min}$.

PCR products of 1400 and $3000 \mathrm{bp}$ were digested with 22 restriction enzymes (Hae III, Msp I, Hpa II, Bam HI, Eco RI, Mse I, Alu I, Hind III, Kpn I, Dde I, Dra I, Pst I, Mbo I, Sma I, Xho I, Mnl I, Bfa I, Hha I, Aci I, Rsa I, Sac II, Tsp 509 I). Digestions were carried out overnight with $2 \mathrm{U}$ of each enzyme, fragments were separated on $1.5 \%$ agarose gels and visualised using ethidium-bromide staining.

Cleaned PCR products (Sephadex G-50 columns) were sequenced using an ABI Prism 377 Automated DNA Sequencer and the Dye Primer labelling kit protocol provided by Applied Biosystems, in order to check for mtDNA identity. Sequencing reactions were in $5 \mu \mathrm{l}$ volumes containing $25 \mathrm{ng}$ initial PCR product, $1.25 \mathrm{pmol}$ 
primer and $2.5 \mu \mathrm{l}$ of $\mathrm{FS}$ dye terminator ready reaction cycle sequencer mixture for $\mathrm{ABI}$. The PCR profile was $94^{\circ} \mathrm{C}$ for $1 \mathrm{~min}, 25$ cycles of $94^{\circ} \mathrm{C}$ for $1 \mathrm{~min}$, $60^{\circ} \mathrm{C}$ for $30 \mathrm{~s}, 72^{\circ} \mathrm{C}$ for $55 \mathrm{~s}$ and one final cycle at $72^{\circ} \mathrm{C}$ for $7 \mathrm{~min}$. The nature of the mitochondrial sequences was confirmed by a BLAST search. Both sequences corresponded to insect mitochondrial DNA (regions 12 Sai and $\mathrm{COI})$.

\section{AFLP data analysis}

In Genographer (Benham, 1999) we visually scored the presence and absence of bands using the Thumbnail option. We obtained a $0 / 1$ matrix for each primer separately and then combined them. The resulting $0 / 1$ data matrix was used in TREECON (Van de Peer and De Wachter, 1994) to estimate genetic distances estimates representing all possible pairwise comparisons of individuals within and among localities using Nei-Li distance coefficient (Nei and Li, 1979). The advantage of using Nei and Li distance estimation is that it includes only the shared presence of a band and excludes the absence of a band which can have many reasons (eg substitution, deletion, insertion, etc). The number of polymorphic and monomorphic bands was determined for each primer pair. STATISTICA 5.5 was used for statistical analyses. A UPGMA tree was constructed based on genetic distances in TREECON.

\section{Results}

Gene transfer from males to thelytokous females under laboratory conditions

Our laboratory experiments showed that it was possible to mate thelytokous females with males of arrhenotokous strains. Dissection of spermatheca of a subset of females demonstrated that sperm transfer had taken place in 22 of $38(58 \%)$ matings. Subsequent genetical analyses using parental specific markers proved that mated thelytokous females incorporate the male's chromosomes in some of their offspring. All these females produced only daughters, except for two females that, in addition, produced one son each. $\mathrm{F}_{1}$ daughters were of two types; those with the maternal genotype were considered the product of unfertilised parthenogenetic eggs, those with both maternal and paternal markers were scored as developed from fertilised eggs. The two $F_{1}$ males are difficult to account for (see below and the Discussion).

The results of the crosses between thelytokous females and arrhenotokous males are shown in Figure 1. Of the $50 \mathrm{VLP}+/+$ females $\times$ VLP - males crosses, 13 produced a mixed brood containing a total of 110 homozygous + / + females, 54 heterozygous +/ - females and 2 - males. The others yielded only monotypic progenies with the maternal marker or no offspring of the 11 VLP - females $\times$ VLP + males, one yielded a
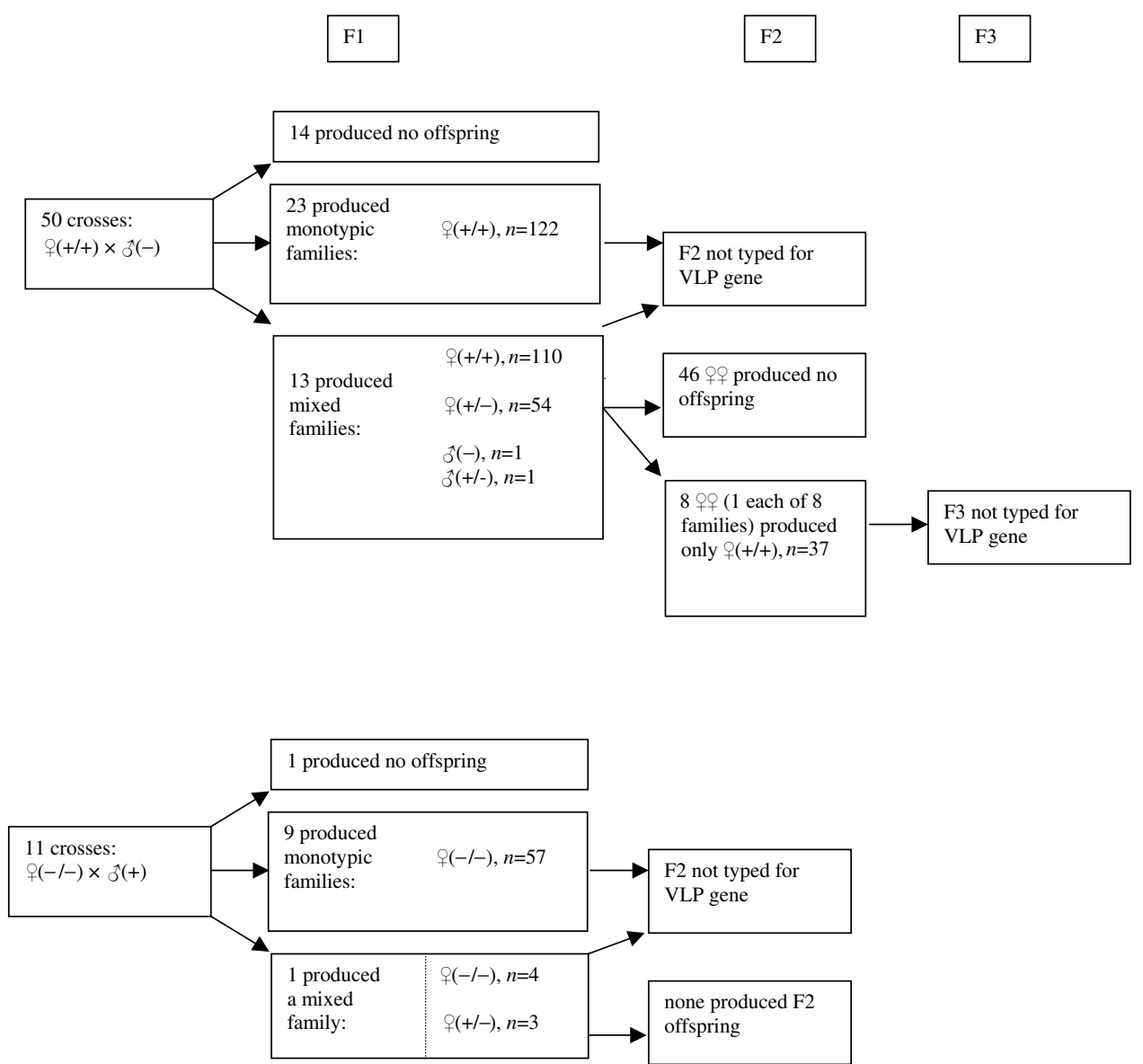

Figure 1 Summary of the laboratory crosses between arrhenotokous males and thelytokous females. 
mixed brood of 4 homozygous - / - females and three heterozygous $+/-$ females. This means that the paternal VLP marker allele was present in the offspring of 14 out of 61 families (22.9\%), totalling 57 individuals out of 352 (16.2\%) $\mathrm{F}_{1}$ offspring tested. Inspection of the intensities of the bands on the gels suggested that all female offspring were diploid. Monotypic $F_{1}$ families with only the maternal VLP allele $(+/+$ or $-/-)$ were not typed further in the $F_{2}$ generation. Similarly, $F_{1}$ females of mixed broods that were homozygous for the maternal allele were considered the product of parthenogenesis, and not typed further. In the VLP $+/+$ female $\times$ VLP male crosses only eight of the 54 heterozygous $(+/-) \mathrm{F}_{1}$ females, each of a different family produced $\mathrm{F}_{2}$ offspring. They produced $37+/+$ daughters and no sons, indicating that these 'hybrid' females reproduced thelytokously. Surprisingly, the paternally derived minus allele was lost in all cases. In the reverse cross, the three heterozygous $\mathrm{F}_{1}$ females did not produce any progeny.

Prompted by the unexpected finding of the loss of the paternal VLP allele in $\mathrm{F}_{2}$ offspring, we used the multilocus AFLP method for checking the validity of the VLP screening. Table 1 shows the frequencies of the unique paternal AFLP bands that occurred in the progenies of five of the 50 crosses between a thelytokous female and a male. The number of unique bands of the father compared to that of its female partner varied from 3 to 27. The mean number of the unique father bands in successive generations remained more or less constant. For a number of practical reasons, it was not possible to follow each family up to the fourth generation and therefore sample sizes are rather small. Four $F_{1}$ females with only the maternal VLP type were also AFLP analysed. No bands of the father occurred in any of them. These data show that male genes were stably incorporated into thelytokous lines for at least up to four generations.

\section{Gene transfer from males to thelytokous females in the field}

The AFLP analysis of offspring of field females that had oviposited in the baits, yielded a total of 76 reliably scorable bands. The monomorphic bands and the bands that were present or absent in only one sample were excluded from the analysis, leaving 62 bands polymorphic in more than one individual. A total of 41 wasps were analysed; 28 arrhenotokous and 13 thelytokous ones. They originated from many different baits in the three transects and their sample dates were evenly spread over the season (Schneider unpublished). Both AFLP primer combinations gave similar estimates of genetic similarity. Therefore, the combined set of poly- morphic bands of both primer combinations was used to calculate the genetic distance matrix. An UPGMA tree based on the combined genetic distance matrices is shown in Figure 2. The distribution of the thelytokous wasps in the tree does not differ significantly from random ( $P=0.49$, bootstrap analysis with 10000 runs). This implies that at the nuclear level thelytokous wasps were not more related to each other than to their arrhenotokous sympatrics. It suggests either a frequent arisal of thelytoky from the arrhenotokous population or gene flow between the arrhenotokous and thelytokous population.

Evidence that such gene flow is not leading to complete homogenisation of genetic variation between both modes comes from the VLP data (Figure 2, Table 2). All 13 thelytokous wasps were VLP - / - whereas all three genotypic classes were more or less equally represented among the 28 arrhenotokous wasps. Frequencies of the VLP + and - alleles were significantly different in both modes $\left(\chi^{2}=15.6, P=0.001\right)$.

Of the 22 restriction enzymes used in the analysis of mitochondrial DNA, 12 cut fragment 1 (COI-COII), but only one (Hae III) resulted in polymorphism. In all, 10 enzymes restricted fragment 2 (ND4-12 Sai), but two (Eco RI and Dde I) produced polymorphism. A clear pattern was found in that two haplotypes resulting from the combination of all three enzymes could be distinguished. They are coded as haplotype I (Hae III (1150, 1000 and $300 \mathrm{bp})$, Eco RI (3000 bp) and Dde I (1500, 1100 and $200 \mathrm{bp})$ ) and haplotype II (Hae III (1400 bp), Eco RI (2100 and $800 \mathrm{bp}$ ) and Dde (1500, 1300, 1100, 800, 300 and $200 \mathrm{bp})$ ). Unambiguously, all arrhenotokous wasps had haplotype II, whereas all thelytokous wasps showed haplotype I (Figure 2). Thus, at the mitochondrial level, the two modes were completely dissimilar.

\section{Discussion}

This study has shown that gene transfer from arrhenotokous males to stable thelytokous lineages can occur in laboratory populations of $V$. canescens. Results also showed that such gene flow occurs under natural conditions. Belshaw et al (1999) concluded from a molecular analysis of field samples of several closely related arrhenotokous and thelytokous parasitoid species of the genus Lysiphlebus that occasional sexual processes must have occurred between the two reproductive modes. However, since they did not perform mating experiments, their work provided only indirect evidence. To our knowledge, our study is the first showing direct evidence for gene flow between arrhenotokous and thelytokous populations in an insect parasitoid.

Table 1 Inheritance of unique father AFLP bands in the offspring of crosses between arrhenotokous males and thelytokous females

\begin{tabular}{lcccc}
\hline Family & No. of unique father bands & $F 1$ & $F 2$ & $F 3$ \\
\hline 1 & 6 & $4.6 \pm 1.1(7)$ & $5.0 \pm 0(2)$ & \\
2 & 3 & $3 \pm 0(3)$ & & \\
3 & 14 & $6.0 \pm 0(3)$ & $4.4 \pm 1.4(24)$ & $4.5 \pm 0.6(4)$ \\
4 & 27 & $15.6 \pm 6.8(3)$ & $14 \pm 5.6(2)$ & $20 \pm 0(2)$ \\
5 & 3 & $2.6 \pm 0.6(4)$ & & $20 \pm 0(1)$ \\
\hline
\end{tabular}

Numbers are averages \pm SD and sample sizes in brackets. 


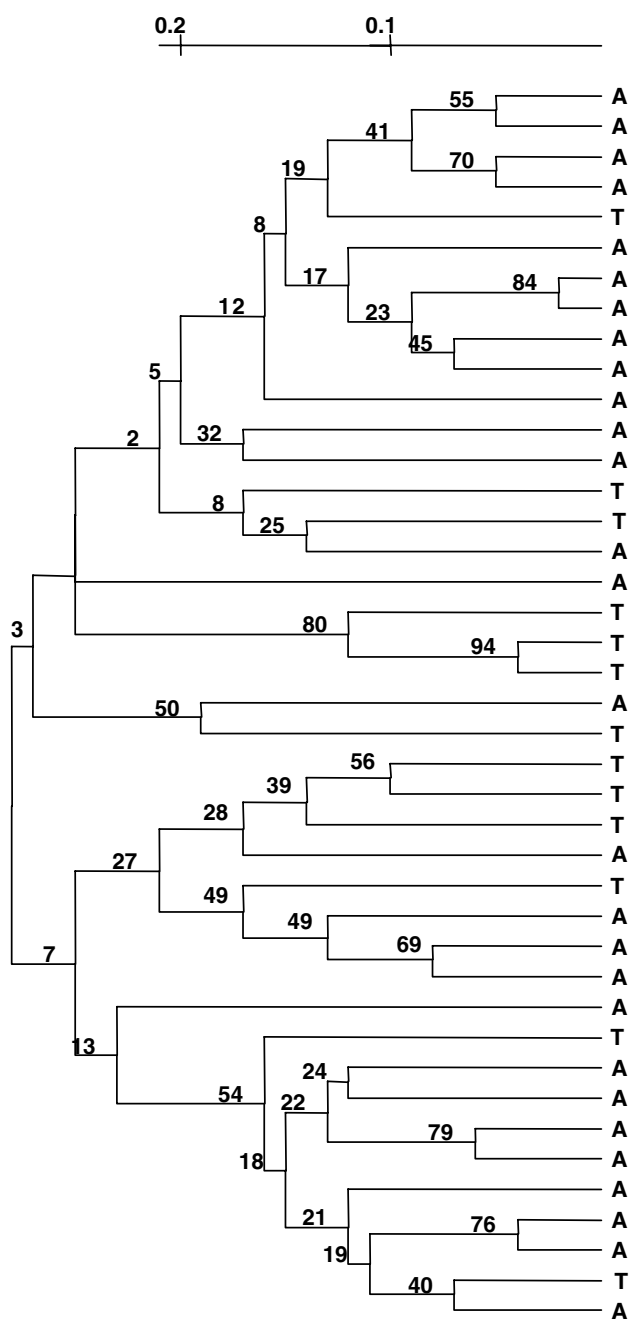

$\begin{array}{ll}\text { II } & - \\ \text { II } & +- \\ \text { II } & + \\ \text { II } & - \\ \text { II } & +- \\ \text { II } & ++ \\ \text { II } & +- \\ \text { II } & +- \\ \text { II } & - \\ \text { II } & +- \\ \text { II } & ++ \\ \text { II } & ++ \\ \text { I } & -- \\ \text { I } & - \\ \text { II } & ++ \\ \text { II } & - \\ \text { I } & - \\ \text { I } & - \\ \text { I } & - \\ \text { II } & - \\ \text { I } & - \\ \text { I } & - \\ \text { I } & -- \\ \text { I } & -- \\ \text { II } & +- \\ \text { II } & -- \\ \text { II } & ++ \\ \text { II } & +- \\ \text { II } & ++ \\ \text { II } & - \\ \text { I } & - \\ \text { II } & -- \\ \text { II } & +- \\ \text { II } & - \\ \text { II } & +- \\ \text { II } & - \\ \text { II } & ++ \\ \text { II } & - \\ \text { I } & - \\ \text { II } & +- \\ \text { II } & +\end{array}$

Figure 2 UPGMA tree based on the genetic distance matrix $\mathrm{T}=$ thelytokous wasps, $\mathrm{A}=$ arrhenotokous wasps, $\mathrm{I}=\mathrm{mtDNA}$ haploype $\mathrm{I}$, $\mathrm{II}=$ mtDNA haplotype II, VLP = virus-like protein allele. Number on the branches are bootstrap values.

Table 2 VLP genotypes and allele frequencies in thelytokous and arrhenotokous females caught in the sampling area

\begin{tabular}{lcccccc}
\hline Reproductive mode & \multicolumn{2}{c}{ VLP genotype } & & \multicolumn{2}{c}{ VLP allele frequencies } \\
\cline { 2 - 3 } \cline { 6 - 7 } & $-/-$ & $+/-$ & $+/+$ & & - & + \\
\hline Thelytoky & 13 & 0 & 0 & & 26 & 0 \\
Arrhenotoky & 10 & 10 & 8 & & 30 & 26
\end{tabular}

Our VLP data showed that mating between arrhenotokous males and thelytokous females did not always lead to gene transfer: in around $70 \%$ of the crosses, the paternal VLP marker was not present in the $F_{1}$. This could be because of either sperm not being transferred during mating or sperm not being used by the females after mating. Data on insemination rates, based on dissection of thelytokous females after observed matings, showed that $58 \%(n=38)$ of the matings resulted in sperm transfer. Inseminated thelytokous females ferti- lised fewer eggs than standard arrhenotokous females. The overall transmission rate of the paternal VLP-marker (16.2\% excluding the two males) was much lower than the normal fertilisation proportion under the current laboratory conditions (approximately 50\%, Beukeboom, 2001) of arrhenotokous females. This indicates that successful egg fertilisation is somehow reduced in thelytokous females, which could have several causes including partial egg-sperm incompatibility and partial degeneration of the fertilisation capacity because of relaxed selection under thelytoky.

The production of two VLP - males by mated thelytokous females is hard to account for. Both males were in a progeny consisting of uniparentally and biparentally produced females. Since males normally develop from unfertilised eggs in arrhenotokous Hymenoptera they are expected to share only the genes of their mothers who in this case were $+/+$. Unfortunately, we could not unequivocally determine their ploidy level, leaving many possible explanations. For example, haploid males could be because of hold of restitution upon fertilisation of the egg and subsequent failure to 
incorporate the sperm nucleus. Diploid males may be because of homozygosity at the sex locus after normal fertilisation by a sperm with a similar sex allele (Beukeboom, 2001). However, these possibilities do not explain why the males had only the paternal VLP allele. More clarity will come from our current investigation of the cytology of the fertilisation process in eggs of thelytokous females.

Only two different mitochondrial haplotypes were found even though many enzymes cut the amplified fragments. Each type was exclusively found in one reproductive mode. Although no arrhenotokous wasps with haplotype I were found at this sampling scale, they have been found in other areas in the Côte $d^{\prime}$ Azur (Schneider, unpublished). This shows that the arrhenotokous wasps caught in our transects are not the progenitors of the thelytokous wasps in this area. However, the resemblance at the nuclear DNA level between both modes indicates local gene flow from the arrhenotokous to the thelytokous wasps. This gene flow appears to be unidirectional, which is in agreement with the laboratory data. Our standard cultures of various arrhenotokous lines that have been kept for more than 10 years have yielded tens of thousands of wasps. We never observed a spontaneous arisal of thelytoky in these cultures, which suggests that this is a very rare event in this species.

Thelytoky in $V$. canescens is known to preserve a certain degree of heterozygosity depending on the position of the locus on the chromosome (Beukeboom and Pijnacker, 2000). The cytological mechanism of thelytoky (automixis with diploidy restoration by metaphase I restitution) will lead to an increase in homozygosity of the genome in successive generations and a consequential loss of genetic variability in thelytokous lineages. Our VLP distribution data are relevant in this respect. The current data corroborate previous ones showing geographical differences in frequencies of both VLP alleles (Malmberg et al, 2000). Interestingly, thelytokous females heterozygous for the VLP gene have never been found, while heterozygous arrhenotokous females are abundant. This suggests that the VLP locus becomes quickly homozygous in thelytokous individuals, likely because of its genomic location close to a telomere.

In conclusion, the main factor accounting for the genetic variation found in natural populations of thelytokous $V$. canescens seems to come from matings between males and thelytokous females. Gene transfer from arrhenotokous males to thelytokous females helps to understand the previously described relatedness between arrhenotokous and thelytokous populations in the Côte d'Azur region (Schneider et al, 2002). This study shows that both reproductive modes are not fully genetically isolated in the field. Occasional replenishment of genetic variation in thelytokous populations may counterbalance the putative long-term disadvantages of thelytokous reproduction. Our data therefore accentuate the paradox of sex in this species. Most theories about the maintenance of sex are based on the evolutionary benefit of sexual recombination (Kondrashov, 1993). If thelytokous females can occasionally benefit from incorporation of genes of arrhenotokous individuals, this advantage of sexuals diminishes, making it harder to explain the persistence of sexual populations of $V$. canescens. Studies comparing life histories of both modes may shed light on this problem.

\section{Acknowledgements}

We thank $H$ Breuwer for preliminary work on the mtDNA-PCR and M Maan for comments on the manuscript. This research was supported by the Netherlands Science Foundation Grants nos. ALW 809.34.007.

\section{References}

Barton NH, Charlesworth B. (1998). Why sex and recombination? Science 281: 1986-1989.

Bell G (1985). Two theories of sex and variation. Experientia 41: 1235-1245.

Belshaw R, Quicke DLJ, Volkl W, Godfray HCJ (1999). Molecular markers indicate rare sex in a predominantly asexual parasitoid wasp. Evolution 53: 1189-1199.

Benham J (1999). Genographer (version 1.1.0) [WWW document]. URL http://hordeum.oscs.montana.edu/genographer.

Beukeboom LW (2001). Single-locus complementary sex determination in Venturia canescens (Hymenoptera: Ichneumonidae). Neth J Zool 51: 1-15.

Beukeboom LW, Driessen G, Luckerhoff L, Berstein C, Lapchin L, van Alphen JJM (1999). Distribution and relatedness of sexual and asexual Venturia canescens (Hymenoptera). Proc VIIIth Meeting Exp Appl Entomol Neth 10: 23-28.

Beukeboom L, Pijnacker LP (2000). Automictic parthenogenesis in the parasitoid Venturia canescens (Hymenoptera: Ichneumonidae) revisited. Genome 43: 939-944.

Bierzychudek P (1985). Patterns in plant parthenogenesis. Experientia 41: 1255-1264.

Bierzychudek P (1989). Environmental sensitivity of sexual and apomictic Antennaria: do apomicts have general-purpose genotypes? Evolution 43: 1456-1466.

Bonsall MB, Hassell MP (1998). Population dynamics of apparent competition in a host-parasitoid assemblage. $J$ Anim Ecol 67: 918-929.

Browne RA (1992). Population genetics and ecology of Artemia: insights into parthenogenetic reproduction. Trends Ecol Evol 7: 232-237.

Charlesworth D, Morgan MT, Charlesworth B (1993). Mutation accumulation in finite populations. J Hered 84: 321-325.

Cline LD, Flaherty BR, Press JW (1983). Response of parasitoids and predators of stored-product insects to whitelight or blacklight traps. J Econ Entomol 76: 298-301.

Cook JM (1993). Sex determination in the Hymenoptera: a review of models and evidence. Heredity 71: 421-435.

Corley LS, Blankenship JR, Moore AJ (2001). Genetic variation and asexual reproduction in the facultatively parthenogenetic cockroach Nauphoeta cinerea: implications for the evolution of sex. J Evol Biol 14: 68-74.

Corley LS, Moore AJ (1999). Fitness of alternative modes of reproduction: developmental constraints and the evolutionary maintenance of sex. Proc $R$ Soc Lond B 266: 471-476.

Crozier RH (1971). Heterozygosity and sex determination in haplodiploidy. Am Nat 105: 399-412.

Driessen G, Bernstein C, van Alphen JJM, Kacelnik A (1995). A count down mechanism for host search in the parasitoid Venturia canescens. J Anim Ecol 64: 117-125.

Delmotte F, Leterme N, Bonhomme J, Rispe C, Simon JC (2001). Multiple routes to asexuality in an aphid species. Proc $R$ Soc Lond B 268: 2291-2299.

Dybdahl MF, Lively CM (1995). Diverse, endemic and polyphyletic clones in mixed populations of freshwater snail (Potamopyrgus antipodarum). J Evol Biol 8: 385-398.

Freeman P (1980). Common Insect Pests of Stored Food Products, British Museum (Natural History), 6th edn. Economic Series London: London. 
Goater B (1986). British Pyralid Moths - a Guide to their Identification. Harley Books: Colchester, UK.

Harvey JA, Thompson DJ (1995). Developmental interactions between the solitary endoparasitoid Venturia canescens (Hymenoptera: Ichneumonidae), and two of its hosts, Plodia interpuctella and Corcyra cephalonica (Lepidoptera: Pyralidae). Eur J Entomol 92: 427-435.

Harvey JA, Vet LEM (1997). Venturia canescens parasitizing Galleria mellonella and Anagasta kuehniella: differing suitability of two hosts with highly variable growth potential. Entomol Exp Appl 84: 93-96.

Hellers M, Beck M, Theopold U, Kamei M, Schmidt O (1996). Multiple alleles encoding a virus-like particle protein in the ichneumonid endoparasitoid Venturia canescens. Ins Mol Biol 5: 239-249.

Hurst LD, Peck JL (1996). Recent advances in understanding of the evolution and maintenance of sex. Trend Ecol Evol 11: 4145.

Innes DJ, Hebert PDN (1988). The origin and genetic basis of obligate parthenogenesis in Daphnia pulex. Evolution 42: 10241035.

Jokela J, Lively CM, Dybdahl MF, Fox JA (1997). Evidence for a cost of sex in the freshwater snail Potamopyrgus antipodarum. Ecology 78: 452-460.

Kondrashov AS (1988). Deleterious mutations and the evolution of sexual reproduction. Nature 336: 435-441.

Kondrashov AS (1993). Classification of the hypotheses on the advantages of aphimixis. J Heredity 84: 372-387.

Kramer MG, Templeton AR (2001). Life-history changes that accompany the transition from sexual to parthenogenetic reproduction in Drosophila mercatorum. Evolution 55: 748-761.

Lamb RY, Willey RB (1979). Are parthenogenetic and related bisexual insects equal in fertility? Evolution 33: 774-775.

Legner EF (1985). Effects of scheduled high temperature on male production in thelytokous Muscidifurax uniraptor (Hymenoptera Pteromalidae). Can Entomol 117: 383-389.

Leslie JF, Vrijenhoek RC (1980). Consideration of Muller's ratchet mechanism through studies of genetic linkage and genomic compatibilities in clonally reproducing Poeciliopsis. Evolution 34: 1105-1115.

Lively CM (1987). Evidence from a freshwater snail for the maintenance of sex by parasitism. Nature 328: 519-521.

Lively CM, Craddock C, Vrijenhoek RC (1990). Red Queen hypothesis supported by parasitism in sexual and clonal fish. Nature 344: 864-866.

Lynch M (1984). Destabilizing hybridization, general-purpose genotypes and geographic parthenogenesis. Q Rev Biol 59: 257-290.

Malmberg T, Beukeboom LW, Driessen G, van Alphen JJM (2000). Distribution of a VLP-protein polymorphism in sexual and asexual Venturia canescens populations (Hymenoptera). Proc Exp App Entomol N.E.V. Amsterdam 11: 89-93.

Maynard-Smith J (1978). The Evolution of Sex. Cambridge University Press: Cambridge.

Maynard Smith J (1986). Contemplating life without sex. Nature. 356: 661-662.

Muller HJ (1964). The relation of recombination to mutational advance. Mutat Res 1: 2-9.

Nei M, Li WH (1979). Mathematical model for studying genetic variation in terms of restriction endonucleases. Proc Natl Acad Sci USA 76: 5269-5273.

Parker ED, Selander RK, Hudson RO, Lester LJ (1977). Genetic diversity in colonising parthenogenetic cockroaches. Evolution 31: 836-842.
Peck JR, Barreau G, Heath SC (1997). Imperfect genes, Fisherian mutation and the evolution of sex. Genetics 145: 1171-1199.

Peck JR, Waxman D (2000). What's wrong with a little sex? J Evol Biol 13: 63-69.

Peck JR, Yearsley JM, Waxman D (1998). Explaining the geographic distributions of sexual and asexual populations. Nature 391: 889-892.

Pongratz N, Sharbel TF, Beukeboom LW, Michiels NK (1998). Allozyme variability in sexual and parthenogenetic freshwater planarians: evidence for polyphyletic origin of parthenogenetic lineages through hybridization with coexisting sexuals. Heredity 81: 38-47.

Press JM, Cline LD, Flaherty BR (1982). A comparison of two parasitoids, Bracon hebetor (Hymenoptera: Braconidae) and Venturia canescens (Hymenoptera: Ichneumonidae), and a predator Xylocoris flavipes (Hemiptera: Anthocoridae) in suppressing residual populations of the almond moth, Ephestia cautella (Lepidoptera: Pyralidae). J Kans Entomol Soc 90: 725-728.

Schneider MV, Beukeboom LW, Driessen G, Lapchin L, Bernstein C, van Alphen JJM (2002). Geographical distribution and genetic relatedness of sympatrical thelytokous and arrhenotokous populations of the parasitoid Venturia canescens (Hymenoptera). J Evol Biol 15: 191-200.

Slobodchikoff CN (1983). Why asexual reproduction?: variation in populations of the parthenogenetic wasp Venturia canescens. Ann Entomol Soc Am 76: 23-29.

Speicher BR, Speicher KG, Roberts FL (1965). Genetic segregation in the unisexual wasp Devorgilla. Genetics 52: 1035-1041.

Storhas M, Weinzierl RP, Michiels NK (2000). Paternal sex in parthenogenetic planarians: a tool to investigate the accumulation of deleterious mutations. I Evol Biol 13: 1-8.

Stouthamer R, Kazmer DJ (1994). Cytogenetics of microbeassociated parthenogenesis and its consequences for geneflow in Trichogramma wasps. Heredity 73: 317-327.

Suolmalainen E, Saura A, Lokki J (1987) Cytology and Evolution in Parthenogenesis. CRC Press: Boca Raton, FL.

Templeton AR (1979). The unit of selection in Drosophila mercatorum. II. Genetic revolution and the origin of coadapted genomes in parthenogenetic strains. Genetics 92: 1265-1282.

Van de Peer Y, De Wachter R (1994). TREECON for Windows: a software package for the construction and drawing of evolutionary trees for the Microsoft Windows environment. Comput Appl Biosci 10: 569-570.

Van Valen L (1973). A new evolutionary law. Evol Theor 1: $1-30$.

Vos P, Hogers R, Bleeker M, Reijans M, Lee van de T, Hornes M et al. (1995). AFLP: a new technique for DNA fingerprinting. Nucleic Acid Res 23: 4407-4414.

Vrijenhoek RC (1979). Factors affecting clonal diversity and coexistence. Am Zool 19: 787-797.

Vrijenhoek RC (1999). Parthenogens and natural clones. Encycl Reprod 3: 695-702.

Waage JK (1979) Foraging for patchily distributed hosts by the parasitoid Nemeritis canescens. J Anim Ecol 48: 353-371.

Werren JH (1997). Wolbachia run amok. Proc Natl Acad Sci 94: 11154-11155.

West SA, Lively CM, Read AF (1999). A pluralist approach to sex and recombination. J. Evol Biol 12: 1003-1012.

Whiting, PW (1943). Multiple alleles in complementary sex determination of Habrobracon. Genetics 28: 365-382.

Williams GC (1975). Sex and Evolution, Princenton University Press: Princeton, MA. 